Teresa Siek-Piskozub

Uniwersytet im. Adama Mickiewicza w Poznaniu

piskozub@amu.edu.pl

\title{
KOMPETENCJA MIĘDZYKULTUROWA - KONCEPCJE I WYZWANIA
}

\section{Intercultural competence: concepts and challenges}

One of the goals of foreign language education is to prepare learners to the role of intercultural mediators, as indicated in such documents as National Standards for Foreign Language Education or The Common European Framework of Reference for Languages. Research on culture and its relation to language has a long tradition and reveals a complex and also dynamic nature of the concept. Culture has also been present, although to a different extent, in the long practice of foreign language teaching. However, our understanding of cultural competence in a multicultural and multilingual European Union, which sets goals in the area of education in its Member States, has been evolving. In the article we will discuss different concepts of culture proposed by such researchers as Hofstede (1980, 1991), Binnett (1993), Weaver (2001), and Byram (1997), as well as various concepts of approaching culture in the foreign language education context. We will also look at challenges faced by Polish learners and teachers in the foreign language classroom.

Keywords: culture models, intercultural competence, ethnographic approach, analysis of literary texts, comparative approach, socio-constructivist approach

Słowa kluczowe: modele kultury, kompetencja międzykulturowa, podejście etnograficzne, analiza tekstu literackiego, podejście porównawcze, podejście społeczno-konstruktywistyczne 


\section{Wstęp}

Jednym z celów współczesnej glottodydaktyki jest przygotowanie nauczycieli i uczniów do roli mediatora międzykulturowego, co wynika zarówno z dokumentów Wspólnoty Europejskiej, np. National Standards for Foreign Language Education $(1996,1999)$ i polskiej wersji The Common European Framework of Reference for Languages (Europejski System Opisu Kształcenia Językowego, 2003), jak i (w prawdzie w mniejszym stopniu) z dokumentów polskich, jak Podstawa programowa, 2009, Dziennik Ustaw Nr 4, poz. 17). Kultura od początku praktyki nauczania języka była obecna na lekcjach, czego dowodem jest tzw. metoda filologiczna, najstarsza z opisanych przez Traka w traktacie gramatycznym Téchnē gramatiké już w I wieku przed naszą erą. Z czasem ewoluowała i znana była wpierw jako metoda klasyczna, a bardziej współcześnie - jako metoda gramatyczno-tłumaczeniowa, polegająca na egzegezie tekstu pisanego, którym początkowo był jakiś większy lub mniejszy fragment tekstu literackiego (Puppel, 2007: 12). To, co zmieniło się w nauczaniu języka, to rozumienie kultury już nie jako osiągnięć danej grupy etnicznej, tzw. kultura przez duże „K” (wyższa, obiektywna), której jednym z przejawów jest twórczość literacka, ale jako ogółu uwarunkowań, w jakich ta grupa funkcjonuje, a więc też kultura przez małe „k” (niższa, subiektywna). Świadomość różnic kulturowych i otwarty stosunek do Innych, a nie tylko znajomość systemu językowego czy sprawności komunikacyjne w języku obcym pozbawione kontekstu kulturowego, stają się celem edukacji obcojęzycznej. Tym bardziej, że, jak słusznie zauważa Hall (1959: 29), kultura jest komunikacją, a komunikacja jest kulturą. Dostrzega się, że istnieje wiele punktów stycznych kultury i języka, co Liddicoat przedstawił w formie kontinuum ukazującego powiązania kultury i języka w każdym jego aspekcie: wiedzy o świecie dotyczącym danego kontekstu kulturowego, strukturze tekstu mówionego i pisanego, zgodności z normami pragmatycznymi wypowiedzi, zasadami interakcji wpływającymi na dobór i organizację jednostek systemu językowego i wreszcie w poszczególnych komponentach systemu języka oraz komponentach parajęzykowych (Liddicoat i in., 2003) ${ }^{1}$.

Kultury różnią się między sobą i znajomość różnic z tego wynikających jest niezbędna dla skutecznej komunikacji użytkowników języka obcego wywodzących się z innych kręgów kulturowych. W artykule omówimy wybrane cztery modele (między)kulturowości proponowane przez takich badaczy jak Hofstede, Binnett, Weaver i Byram, by zwrócić uwagę na złożoność i dynamiczny

1 Jednymi z pierwszych, którzy zwrócili uwagę na związki kultury i języka, byli Sapir (1884-1939) i Whorf (1897-1941), którzy sformułowali hipotezę relatywizmu językowego (Sapir, 1921; Whorf, 1956). 
charakter kompetencji międzykulturowej. Omówimy też proponowane przez glottodydaktyków podejścia do rozwoju owej kompetencji.

\begin{tabular}{|l|c|c|c|c|}
\hline Culture & \multicolumn{3}{|c|}{ Language } \\
\hline world knowledge & $\begin{array}{c}\text { spoken/ } \\
\text { written genres }\end{array}$ & pragmatic norms & $\begin{array}{c}\text { norms of } \\
\text { interaction }\end{array}$ & $\begin{array}{c}\text { grammar/lexicon } \\
\text { prosody } \\
\text { pronunciation/ } \\
\text { kinesics }\end{array}$ \\
Culture in context & $\begin{array}{c}\text { Culture in general } \\
\text { text structure }\end{array}$ & $\begin{array}{c}\text { Culture within } \\
\text { utterances }\end{array}$ & $\begin{array}{c}\text { Culture in the } \\
\text { organisation and } \\
\text { selection of units of } \\
\text { language }\end{array}$ & $\begin{array}{c}\text { Culture in } \\
\text { linguistic and } \\
\text { paralinguistic } \\
\text { structures }\end{array}$ \\
\hline
\end{tabular}

Rysunek 1: Związki kultury i języka (Liddicoat i in., 2003: 9).

Kompetencja międzykulturowa oraz komunikacja interlokutorów pochodzących z różnych kręgów kulturowych jest jednym z popularniejszych tematów badawczych i prac dyplomowych (licencjackich, magisterskich czy doktorskich). Wielość publikacji na temat kompetencji kulturowej pojawiających się w ostatnim dwudziestoleciu (w tym również w ostatnich latach w czasopiśmie PTN „Neofilolog”) nie oznacza jednak, że nie ma już problemu z jej rozwojem, na co wskazują liczni badacze (np. Aleksandrowicz-Pędich, 2009; Róg, 2013; Szczepaniak-Kozak, 2010). Skupimy się zatem również na różnego rodzaju wyzwaniach, z jakimi muszą się zmierzyć nauczyciele języka chcący włączyć się w proces rozwoju międzykulturowej kompetencji komunikacyjnej swoich uczniów, tj. na problemach natury etycznej, politycznej i edukacyjnej.

\section{Modele (między)kulturowości}

Badacze kultury zwrócili uwagę na problemy z komunikacją między reprezentantami różnych kultur spowodowane nie tyle trudnościami językowymi, ile inną strukturą mentalną uczestników procesu komunikacyjnego. Podejmowali badania nad istotą owych różnic (np. Hofstede, 1980, 1991), nad rozwojem wrażliwości międzykulturowej (Bennett, 1993) czy też genezą problemów z komunikacją międzykulturową (Weaver, [1997] 2001). Różne te koncepcje zostały uwzględnione w materiałach opracowanych na zamówienie Rady Europy do wykorzystania w kształceniu młodzieży (np. Martinelli i Taylor, 2000).

W latach 70. ubiegłego wieku, odpowiadając na zamówienie międzynarodowej korporacji, Hofstede przeanalizował cechy charakterystyczne dla 50 
kultur etnicznych i trzech regionów, po czym wyodrębnił pięć czynników², które różnicują kultury i mają wpływ na wzajemne porozumienie: dystans władzy/społeczny (ang. power distance), unikanie niepewności (ang. uncertainty avoidance), indywidualizm lub kolektywizm (ang. individualism vs. collectivism), dominacja kultury męskiej lub kobiecej (ang. masculinity vs. feminity) oraz podejście do czasu (ang. time orientation). Analizując różne kultury, autor lokował je na wykresach, które przedstawiały kontinuum danej cechy i pozwalały dostrzec relacje pomiędzy grupami etnicznymi i potencjalnymi niebezpieczeństwami w przypadku kontaktów (Martinelli i Taylor, 2000: 20-22). Na przykład społeczeństwo amerykańskie charakteryzuje indywidualizm, podczas gdy społeczeństwom azjatyckim bliższy jest kolektywizm. Jeśli chodzi o czynnik czasu, to anegdotycznie można stwierdzić, że jedne kultury posiadają zegarki (np. brytyjska, germańska) a inne - czas (np. arabska, iberyjska). The Hofstede Centre oferuje na stronie internetowej możliwość dokonywania porównań między wybranymi krajami, w tym z Polską, w zakresie sześciu cech (dodatkową cechą jest pobłażliwość, ang. indulgence) (http://geert-hofsted.com/Poland.html).

W modelu tym kultura jawi się jako zjawisko statyczne, charakteryzujące daną grupę etniczną niezależnie od czasu realnego, dając jej poczucie stabilności. Liczni badacze (np. Munoz i Luckmann, 2005: 198) zwracają jednak uwagę, że wprawdzie kultura daje poczucie bezpieczeństwa i stabilności, ale żadna nie jest statyczna, a grupy kulturowe poddawane są różnego rodzaju wyzwaniom związanym z zakłóceniem środowiska naturalnego, z procesami społecznymi, jak migracje i emigracje, czy też z wojnami. Wszystko to ma wpływ na ewolucję kultury i stereotypów jej dotyczących, polegającą na uzupełnianiu starszej koncepcji o nowe cechy dotyczące danej grupy etnicznej, co potwierdziły np. badania Bartmińskiego (2009) nad stosunkiem Polaków do Niemców.

Wpływ kontaktów międzykulturowych na zmianę osobistego postrzegania kultury własnej i obcej badał Bennett (1993). Interesowało go, co się dzieje z osobami poddanymi oddziaływaniu innych kultur w dłuższym okresie. Przeanalizował proces rozwoju tzw. wrażliwości międzykulturowej osób, które miały kontakt z inną kulturą. Zauważył, że jest to proces dynamiczny, który prowadzi do stopniowego zaniku postaw etnocentrycznych na korzyść postaw etnorelatywistycznych. Kluczowe dla rozumienia jego koncepcji jest pojęcie różnicowania (ang. differentiation), oznaczające na poziomie osobistym możliwość różnego postrzegania tej samej rzeczy przez różne osoby, a na poziomie globalnym - rozróżnianie między różnymi kulturami wpływającymi na proces postrzegania. Zdaniem tego badacza proces rozwoju wrażliwości kulturowej

\footnotetext{
2 Początkowo badacz zidentyfikował pierwsze cztery cechy (Hofstede, 1980). Następnie typologię uzupełnił o cechę piątą, tj. podejście do czasu (Hofstede, 1991).
} 
zachodzi w sześciu fazach, aczkolwiek możliwe są też zakłócenia i powroty do faz poprzednich. Faza pierwsza to zaprzeczenie istnienia różnic kulturowych i uznania kultury własnej jako jedynej. Istnienia innych kultur się nie dostrzega lub ma się o nich nikłe pojęcie. Jest to stan typowy dla społeczeństw jednojęzycznych, jeśli ich reprezentanci nie mają styczności z innymi kulturami. W stadium drugim następuje obrona własnej kultury jako tej lepszej, bardziej etycznej, rozwiniętej itp. Następuje wewnętrzny podział na "nas" i „innych” oraz uznanie własnej kultury jako tej wyższej. Ale też na tym etapie może nastąpić zamiana (tzw. odwrócenie) i postrzeganie własnej kultury jako gorszej, co zdarza się przy krótkim pobycie w kraju danej kultury i zafascynowaniu jej osiągnięciami. Z kolejną fazą - minimalizowaniem różnic - wiąże się przekonanie o uniwersalnej wartości własnej kultury i pomniejszaniu znaczenia dostrzeganych różnic, opinia, że wszyscy jesteśmy w zasadzie do siebie podobni. Bennett stwierdza, że jest to najczęściej spotykany stan w rozwoju kompetencji międzykulturowej. Celem na tym jego etapie, który jest też stanem przejściowym między etnocentryzmem a etnorelatywizmem, jest potrzeba osiągnięcia kulturowej samoświadomości, rozpoznania kontekstu, w którym dane zjawisko zachodzi, a nie generalizowania poza ów kontekst. Kolejna faza to akceptacja różnic kulturowych - świadomość, że kultury są różne, ale jej reprezentanci są równi nam. Jesteśmy w stanie dostrzec wiele różnic kulturowych w kontakcie $z$ ich reprezentantami, choć nie jesteśmy ekspertami w danej dziedzinie. Trzeba wszakże pamiętać, że znajomość różnic nie jest tożsama z ich akceptacją. Na tym etapie charakterystyczną cechą jest uznanie, że różnice kulturowe nas wzbogacają. Adaptacja to następna faza przystosowania się do wymogów kultury, w której dana osoba przebywa, zaakceptowania i podporządkowania się wymogom danego środowiska, co nie oznacza zatracenia własnej tożsamości (tj. asymilacji). Jest to umiejętność przechodzenia między koncepcjami i zachowaniem charakterystycznym dla różnych kultur w zależności od potrzeb kontekstu, w którym dochodzi do interakcji. Bennett zauważa, że fazę adaptacji na ogół osiąga się po co najmniej trzyletnim pobycie w danej kulturze. Ostatnia faza to integracja różnych pojęć, zachowań i poglądów charakterystycznych dla różnych kultur, dostrzeganie własnej kulturowej marginalności, a nie traktowanie własnej kultury jako centralnej. Kramsch (1993) określa ten stan jako zajęcie trzeciego miejsca (pomiędzy dwiema kulturami obcą i rodzimą). O ile w poprzedniej fazie dana osoba znała i korzystała z różnych zachowań właściwych różnym kulturom w odpowiednim kontekście, to $w$ tej fazie następuje próba połączenia owych różnych kultur w jeden spójny system. Osiągnięciu tego stanu towarzyszy często poczucie alienacji, braku przynależności do jakiejkolwiek grupy etnicznej czy wręcz braku zakorzenienia (Martinelli i Taylor, 2000: 28-31). 
Analizując przyczyny nieporozumień międzykulturowych, Weaver ([1997] 2001) przywołuje metaforę góry lodowej jako odzwierciedlenie kultury. To, co jest możliwe do natychmiastowego rozpoznania za pomocą zmysłów, to jej wierzchołek. Tu mieści się cała tzw. kultura obiektywna, jak i widoczne zachowania osób. To, co jest ukryte pod powierzchnią, to kultura subiektywna, system wierzeń i przekonań, wartości, schematów myślowych itp. Jak ocenia Hall (1959: 39), większa część kultury jest ukryta, a zadziwiające jest to, że jest ukryta najskuteczniej przed jej nosicielami. Dlatego też Weaver zauważa, że w komunikacji międzykulturowej dochodzi do zderzenia dwóch gór lodowych, gdzie ich ukryte części zderzają się najwcześniej. Wprawdzie w kontakcie międzykulturowym najpierw zauważa się różnice tam, gdzie są one dostrzegalne, ale to, co prowadzi do rzeczywistych nieporozumień, jest nieuświadomione najczęściej dla obu stron.

Kolejny model, który jest uznawany za model edukacyjny i został wykorzystany zarówno w ESOKJ (2003), jak i w przewodniku adresowanym do nauczycieli i ich edukatorów opracowanym przez międzynarodowy zespół w ramach projektów europejskich (Lázár i in., 2007), to model międzykulturowej kompetencji komunikacyjnej (MKK) Byrama (1997). Jakkolwiek w modelu tym pojawiają się dobrze nam znane komponenty kompetencji komunikacyjnej (lingwistyczny, socjolingwistyczny i dyskursywny), to punktem odniesienia nie jest już rodzimy użytkownik języka, a użytkownik języka drugiego/obcego. Ponadto MKK składa się też z komponentu międzykulturowego, którym jest splot wiedzy, umiejętności i postaw. Ten ostatni czynnik odgrywa istotną rolę w rozwoju MKK. Byram zauważa, że MKK może się rozwijać jako wynik nauczania i kontaktów z kulturą obcą, które mogą, lecz nie muszą, być poprzedzone instruktażem, jak również jako wynik własnych studiów nad kulturą.

\section{Sposoby rozwoju MKK}

Zainteresowanie niezwykle aktualnym we współczesnym świecie problemem międzykulturowości zaowocowało propozycją różnych sposobów jej rozwijania w trakcie zajęć z języka obcego. Omówimy pokrótce wybrane podejścia, choć przenikanie się koncepcji daje się często zauważyć.

Jedną z propozycji jest podejście etnograficzne (np. Byram i Fleming, 1998; Bandura, 2007). Jego zwolennicy sięgają do etnometodologii, w której istotnym narzędziem poznawczym jest dialog (Corbett, 2003: 96). W przeciwieństwie do badań etnograficznych, które mają charakter całościowy, na użytek rozwoju MKK proponuje się zajęcia o charakterze mikroetnograficznym, np. ukierunkowanie uwagi uczących się danego języka na kontekst kulturowy poprzez serię pytań poprzedzających zapoznanie się z tekstem pisanym lub 
przed obejrzeniem scenki na wideo. Inną formą może być etnografia wirtualna, tj. skorzystanie z rozlicznych źródeł internetowych w celu poznania określonego zjawiska kulturowego. Proponowane są też kulturowe asymilatory, tzn. analiza przypadków krytycznych, czyli takich, w których doszło do nieporozumienia wynikającego z różnic kulturowych. W przypadku podróży zagranicznych Bandura (2007: 72) sugeruje prowadzenie dziennika podróży, który pozwala na rejestrowanie zmian w systemie wartości i jest zapisem procesu uczenia się.

Kolejne podejście to analiza tekstów literackich (TL), która różni się wszakże od wspomnianej klasycznej metody filologicznej, gdzie po wokalizacji tekstu następowała szczegółowa i wszechstronna jego analiza z naciskiem na system językowy. Zauważa się, że teksty literackie pozwalają poznać wartości i poglądy osób z innych kręgów kulturowych (Corbett, 2003: 174). W podejściu proponowanym np. przez MacDonalda (2000) zapoznanie się z TL poprzedza aktywacja schematów poznawczych (tj. ćwiczenia poprzedzające czytanie TL, a odwołujące się do posiadanej wiedzy). Po indywidualnym zapoznaniu się z tekstem następuje sprawdzenie jego rozumienia, a następnie dyskusja w mniejszych grupach dotycząca kluczowych problemów w nim zawartych. To pozwala na poznanie różnych punktów widzenia w bezpiecznym środowisku, bo wśród znanych sobie rówieśników. Na koniec następuje poszerzona dyskusja na temat zjawisk typowych dla danej kultury (np. kolonizacji czy feminizmu) na forum całej klasy (MacDonald, 2000: 150). Cirocki (2009) promuje z kolei ekstensywne czytanie dzieł literackich w języku obcym, co w jego propozycji przybiera formę codziennego czytania wybranych utworów w domu przez 45 minut i prowadzenia towarzyszącemu tej czynności notatnika. W klasie natomiast zajęcia mają charakter interaktywny i dotyczą treści lub form językowych występujących w czytanych tekstach. Badacz udokumentował liczne zalety tego podejścia dla rozwoju ogólnej kompetencji językowej, jak również dla kompetencji (między)kulturowej polskich licealistów.

Popularnym podejściem do badań kulturoznawczych i językoznawczych, ale też możliwym do zastosowania w glottodydaktyce, jest podejście porównawcze, tj. zwrócenie uwagi na podobieństwa i różnice odnośnie do danego kontekstu, sytuacji, konstruktu mentalnego czy sprawności językowej, odmiennych dla różnych kultur. Na przykład Gabryś-Barker (2011a) zwróciła uwagę na odmienne postrzeganie kategorii czas w grupie polskiej i portugalskiej, Zawadzka (2004: 186) porównywała rozumienie terminu przyjaciel w języku angielskim, przeciwstawiając mu znaczenie w języku niemieckim i polskim, a Paprocka-Piotrowska (2013) zwróciła uwagę na konceptualizację przestrzeni i związane z tym użycie czasowników ruchu w języku polskim i francuskim. Donesch-Jeżo (2013) porównywała akademicki dyskurs medyczny, aby wskazać różnice polskim studentom medycyny $\mathrm{w}$ trakcie nauczania sprawności pisania $\mathrm{w}$ 
języku angielskim, podczas gdy Kusiak (2013) porównywała rozumienie tekstów w języku polskim i angielskim. Dostępność środków multimedialnych pozwala też na przygotowanie krótkich nagrań w celu prezentacji i analizy zjawisk kulturowych, ze zwróceniem uwagi na podobieństwa i różnice lub np. na analizę reklam ze względu na stereotypy, jakie aktywizują (Paprocka-Piotrowska, 2007).

Możliwe jest też zastosowanie sposobów zgodnych z tzw. podejściem społeczno-konstruktywistycznym (inaczej socjokognitywnym) nawiązującym do koncepcji psychologicznych rozwijanych na początku XX wieku przez Wygotskiego (zob. np. Wygotski, 1989), czy też później przez Brunera (1978), odwołującym się do bezpośredniego doświadczenia jednostki moderowanej przez osobę o większych kompetencjach. Podejście działaniowe może przybierać różne formy, np. przy wykorzystaniu takich technik jak symulacja, drama, prowadzenie portfolio, realizacje projektów międzykulturowych itp. Istotne jest, aby doświadczeniu towarzyszyła refleksja nad zjawiskami kulturowymi (np. Newton, 2012). Scrivener (2011: 19) wymienia pięć kroków porządkujących bezpośrednie doświadczenie. Są to działanie, przypomnienie działania, refleksja dotycząca działania, sformułowanie wniosków, a następnie wykorzystanie ich do kolejnego działania. $W$ ten paradygmat wpisują się też popularne obecnie wymiany międzynarodowe w ramach projektów europejskich (Gabryś-Barker, 2011b; Róg, 2013).

Podejście działaniowe sprawdza się też w przypadku kształcenia przyszłych nauczycieli języków obcych (Siek-Piskozub, 2013; Siek-Piskozub, 2014). Zaangażowanie studentów w symulację nauczania w oparciu o treści międzykulturowe z wykorzystaniem zadań interakcyjnych i problemowych, proponowanych w różnych zbiorach działań rozwijających MKK (np. Brander i in., 1995; Martinelli i Taylor, 2000), poddanych następnie refleksji, umożliwia rozwój wiedzy metakulturowej (Wilczyńska, 2005), prowadzi do ich uwrażliwienia na zjawiska międzykulturowe, rozwija ich gotowość do komunikowania się w języku obcym na wrażliwe tematy, a także doskonali ich umiejętności dydaktyczne (Siek-Piskozub, 2012; Siek-Piskozub, 2013). Dla przemyślenia charakteru zadań i możliwych konfliktów zachodzących pomiędzy różnymi komponentami systemu glottodydaktycznego można wykorzystać koncepcję wywodzącą się od Wygotskiego, a rozwiniętą przez Engeströma (1987) w jego teorii systemu ludzkiej aktywności, którą badacz ilustruje na przykładzie połączonych trójkątów (por. adaptowany dla potrzeb własnych model na rys. 2). Pierwotne w modelu kąty trójkąta: Podmiot, Narzędzia mediacji, Wynik działań (komponenty teorii Wygotskiego) uzupełnił on o Reguły, Społeczność i Podział pracy, a także rozszerzył Wynik o Cel, który może dotyczyć poszczególnych działań, co symbolizuje okrąg oznaczający rozszerzający się krąg wiedzy/umiejętności/postaw. W rezultacie Wynik osiągany jest na końcu procesu. Te komponenty 
modelu są rozpisane na przecinających się i łączących trójkątach. To pozwala na analizę potencjalnych zagrożeń/konfliktów (symbolizują to łączące poszczególne szczyty trójkątów linie), zarówno wewnątrz komponentu (np. różne opinie poszczególnych Podmiotów), a także między komponentami, np. konflikt/różnica opinii na styku Podmiot (uczeń lub nauczyciel) - Społeczność (grupa), Reguły przyjęte przez społeczność - Reguły, które wynikają z zastosowanych w działaniu Materiałów (np. narzucanych ról społecznych czy postaw). Taka analiza pozwoli na przygotowanie się do możliwych napięć przed zajęciami, a po ich przeprowadzeniu - na refleksję nad przyczynami powstałych konfliktów (rysunek 2). Podejście to pozwala na aktywizację studentów (przyszłych nauczycieli) w działania mające na celu rozwój poszczególnych komponentów MKK, co może w przyszłości zaowocować ich inicjowaniem w klasie. Przyzwyczaja też ich do refleksji nad własnym działaniem.

\section{Problemy i wyzwania}

Fakt, że w ostatnim dwudziestoleciu tak wiele pisze się na temat MKK i proponuje się różne ciekawe sposoby jej rozwijania, nie oznacza, że nie mamy już z tym problemu. Zwrócę uwagę na najczęściej podnoszone kwestie.

Jeden z ważnych problemów natury etycznej to wątpliwość, czy mamy prawo ingerować w samoświadomość i samookreślanie się jednostki, a tym bardziej ją oceniać. Jak zauważa Morris-Suzuki (2005: 24-27), choćbyśmy bardzo chcieli się temu przeciwstawić, to zawsze jesteśmy podświadomie zanurzeni w wydarzeniach historycznie związanych z naszą kulturą, nawet jeśli sami ich nie doświadczyliśmy. Może to prowadzić do innego niż oczekujemy postrzegania nas samych, przez pryzmat wyrobionego stereotypu, a nie cech nam indywidualnie właściwych. Potwierdza to w swoim pamiętniku z podróży Japończyk Ryota Nishino (2015), który na próżno starał się budować swoją tożsamość kosmopolity po wielu latach spędzonych na studiach w Australii, aby odciąć się od swojej etnicznej tożsamości, którą - ze względu na okresy imperializmu japońskiego na terenie Azji - postrzegał jako obciążenie. Opisuje on złożoność swoich odczuć w kontakcie z napotkanymi w podróży po krajach azjatyckich interlokutorami i trudność z uwolnieniem się od stereotypu Japończyka. Ponadto tym, którzy zgodnie z modelem Bennetta osiągnęli stan etnorelatywizmu, często towarzyszy poczucie wyobcowania i braku korzeni, jak wynika z twórczości literackiej wielu międzykulturowych pisarzy, np. Hanifa Kureishi (Budda z przedmieścia) czy Johna Updike'a (Terrorysta).

Ostatnio dostrzegamy też słabość polityki promującej wielokulturowość, czego dowodem są ostatnie wypadki we Francji, która jest najbardziej zaangażowana $\mathrm{w}$ jej propagowanie. Podobnego typu sytuacje konfliktowe na 
styku dwóch współistniejących w jednym kraju kultur (zastanej i własnej) ujawniały się i w innych krajach europejskich. Może to mieć wpływ na odrzucenie tej koncepcji. Przykładowo Bennett (2015) dostrzega zmianę w brytyjskim dyskursie politycznym i medialnym na przestrzeni ostatnich dziesięciu lat z charakteru promującego międzykulturowość na oczekiwanie asymilacji przy jednoczesnym ograniczeniu jej możliwości, na co wskazują wywiady z imigrantami. Tym trudniej jest ową koncepcję zaakceptować społeczeństwu, które dotychczas postrzegało się jako monokulturowe. Stąd też obawy wielu członków społeczeństwa polskiego przed umiędzynarodowieniem własnego kraju. Zastanawiające jest też to, że to $\mathrm{w}$ drugim pokoleniu, gdzie można by się już spodziewać integracji kultur, a więc stanu, który Bennett nazwał etnorelatywizmem, rodzi się podatność na fundamentalizmy i radykalizmy wśród młodych ludzi. Prawdopodobnie potrzeba identyfikacji z jakąś kulturą, zakorzenienia w niej, jest tak silna, że rodzi skrajne postawy, które szczególnie łatwo ujawniają się, gdy jednostka ma poczucie dyskryminowania lub wręcz wykluczenia. Problem ten wymaga dokładniejszego zbadania przez psychologów i socjologów i wskazuje na konieczność wczesnego rozwiązywania konfliktów międzykulturowych oraz kształcenia w duchu otwartości w stosunku do Innych.

Glottodydaktyków najbardziej interesują problemy dotyczące kontekstu edukacyjnego. Liczne badania przeprowadzane na stosunkowo małych populacjach wykazują, że polscy nauczyciele nie do końca czują się przygotowani do roli mediatora międzykulturowego (np. Aleksandrowicz-Pędich, 2007; Chłopek, 2009). Ponadto są raczej skłonni nauczać o kulturze etnicznej, którą poznają w trakcie studiów, niż rozwijać MKK, która jawi się im jako coś enigmatycznego. Sygnalizują oni również trapiące ich dylematy etyczne i wskazują na różnego rodzaju problemy, gdy wprowadzają treści niezgodne z przekonaniami wyniesionym z domu, jak wynika choćby z badań Werbińskiej (2009: 26). Brakuje im też zarówno ciekawych materiałów, jak i pomysłów na wprowadzanie treści międzykulturowych, a nade wszystko czasu na ich samodzielne opracowywanie.

Problemy związane z osobą ucznia są nie mniej istotne. Ze względu na zorientowanie polskiej koncepcji edukacji na testowanie kompetencji (a MKK ze względów technicznych, merytorycznych i etycznych na ogół nie jest poddawana ewaluacji), uczniowie nie są zainteresowani MKK. Wydawać by się mogło, że na późniejszych etapach nauczania (w gimnazjum czy liceum) treści kulturoznawcze mogłyby uatrakcyjnić zajęcia, lecz dostrzegany brak motywacji do kontynuowania obowiązkowego uczenia się języka powoduje instrumentalne podejście do przedmiotu (Chłopek, 2008). Werbińska (2009: 27) przywołuje informacje od nauczycieli, że ich uczniowie potrafią wyśmiewać lub negatywnie komentować ilustracje dzieci innych ras, zakłócając tym samym tok lekcji. 
Ponadto, jak wynika np. z badań Roga (2013), uczniowie często przeceniają swoje kompetencje w tym zakresie, na co wskazała samoocena własnej MKK przed udziałem w wymianie międzynarodowej, zweryfikowana następnie po powrocie. Pokazuje to ogrom zadań, jaki stoi przed społeczeństwem polskim, aby właściwie funkcjonować w wielonarodowościowym społeczeństwie Unii Europejskiej. Na to, że można z powodzeniem rozwijać MKK wśród uczniów polskich, wskazują doświadczenia nauczycieli języków obcych kładących nacisk na treści międzykulturowe. Zauważają oni, że w wyniku ich pracy podnosi się poziom MKK nawet u dzieci (Chromiec, 2004; Jaroszewska, 2007), co widać szczególnie u starszych uczniów charakteryzujących się ciekawością poznawczą (Pieklarz, 2005; Romanowski, 2011; Siek-Piskozub, 2012).

Kolejnym problemem są materiały nauczania. Zawadzka (2004: 216) ocenia, że podręczniki do nauczania języka mogłyby w większym stopniu wykorzystywać teksty i ćwiczenia stymulujące porównywanie kultur - obcej i własnej. We współczesnych materiałach problemy kulturowe stanowią obowiązkowy składnik treści nauczania, ale często zawarte są w modułach dodatkowych, nierzadko pomijanych przez nauczyciela lub zostawianych do pracy własnej z braku czasu na zajęciach. Niemniej mój systematyczny ogląd wykorzystywanych podręczników do nauczania języka angielskiego w Polsce, czy to jako ich recenzenta, czy inicjatora prac dyplomowych na ten temat, prowadzi do konstatacji, że następuje stopniowa poprawa w tym zakresie, przynajmniej jeśli chodzi o podręczniki do nauczania języka angielskiego. Przybliżają one kulturę nie tylko krajów anglojęzycznych, stymulują porównania z kulturą własną i tym samym poszerzają wiedzę o świecie. Dlatego też warto sięgać do podręczników nowszych. Ponadto można też korzystać z materiałów uzupełniających, np. pakietów edukacyjnych, które są opracowane w formie scenariuszy zajęć, a dzięki pracom w ramach projektów międzynarodowych są dostępne za darmo w wersji elektronicznej (np. Brander i in., 1995; Martinelli i Taylor, 2000). Warto też, aby nauczyciele różnych języków nauczający w danej szkole współpracowali w tym zakresie, np. w celu opracowania materiałów dotyczących różnych kultur w różnych językach, czy angażowali swych uczniów do porównywania wcześniej ustalonych aspektów kultur nauczanych języków w ramach wspólnych projektów, np. w czasie Europejskiego Dnia Języków.

\section{Podsumowanie}

Nawet tak z konieczności pobieżna analiza złożonego zjawiska międzykulturowości i pojawiających się problemów z jej rozwojem pozwala stwierdzić, że problem ten stanowi wyzwanie. Dotyczy to nas jako społeczeństwa, które przez dziesiątki lat żyło w przekonaniu o swojej jednojęzyczności i monokulturowości, 
nie dostrzegając faktu współistnienia i marginalizując potrzeby mniejszości współżyjących od wieków z naszą kulturą, co - jak pokazała konferencja PTN w 2014 roku - zaczyna się zmieniać. Potrzebna jest natomiast zmiana w mentalności jednostek (zarówno nauczycieli, jak i uczniów), zwiększenia kontaktów międzykulturowych poprzedzonych refleksją nad możliwymi, a po wymianie dostrzeżonymi różnicami kulturowymi. Nie możemy ustawać w poszukiwaniu atrakcyjnych dla uczniów sposobów nauczania. Oznacza to konieczność takiego kształcenia nauczycieli, aby chcieli i potrafili podjąć się roli mediatora międzykulturowego.

\section{BIBLIOGRAFIA}

Aleksandrowicz-Pędich, L. 2007: „Interkulturowość w kształceniu językowym w Polsce i innych krajach europejskich". (w) Nauczanie języków obcych - Polska a Europa. (red. H. Komorowska). Warszawa: Wydawnictwo SWPS Academica, str. 39-56.

Aleksandrowicz-Pędich, L. 2009: „Skuteczność przygotowania studenta filologii angielskiej do roli mediatora kulturowego". (w) Kształcenie językowe w szkolnictwie wyższym. (red. H. Komorowska). Warszawa: Wydawnictwo SWPS Academica, str. 133-149.

Bandura, E. 2007. Nauczyciel jako mediator interkulturowy. Kraków: Tertium.

Bartmiński, J. 2009. Stereotypy mieszkajq w języku. Studia etnolingwistyczne. Lublin: Wydawnictwo UMCS.

Bennett, M. 1993: „Towards ethnorelativism: A developmental model of intercultural sensitivity". (w) Education for the Intercultural Experience. (red. M. R. Paige). Yarmouth, ME: Intercultural Press, str. 21-71.

Bennett, S. 2015. Constructions of migrant integration in British public discourse. Niepublikowana praca doktorska. Poznań: Uniwersytet im. Adama Mickiewicza.

Brander, P. (i in.). 1995. All Different All Equal: Education pack. Ideas, resources, methods and activities for informal intercultural education with young people and adults. Strasbourg: Council of Europe.

Bruner, J. S. 1978. Poza dostarczone informacje. Warszawa: Państwowe Wydawnictwo Naukowe.

Byram, M. 1997. Teaching and Assessing Intercultural Competence. Clevedon: Multilingual Matters.

Byram, M. i M. Fleming (red.). 1998. Language Learning in Intercultural Perspective: Approaches through drama and ethnography. Cambridge: Cambridge University Press.

Cirocki, A. 2009: „Implementing ER approach to literature in the EFL secondary school classroom: An action research study". (w) Extensive Reading in English Language Teaching. (red. A. Cirocki). Muenchen: LINCOM EUROPA, str. 521-545.

Chłopek, Z. 2008: „Intercultural education in a foreign language classroom: Preparing our learners for participation in the multicultural world". (w) Linguistische 
Treffen in Wrocław 2: Linguistica et res cotidianae. (red. I. Bartoszewicz, J. Szczęk i A. Tworek). Wrocław - Dresden: Neisse Verlag, str. 229-240.

Chłopek, Z. 2009. „Nauczanie kultury na lekcjach języka obcego w Polsce: wyniki badań kwestionariuszowych". Języki Obce w Szkole 1: 61-68.

Chromiec, E. 2004. Dziecko wobec obcości kulturowej. Gdańsk: GWP.

Corbertt, J. 2003. Intercultural Language Activities. Clevedon: Multilingual Matters.

Donesch-Jeżo, E. 2013. Akademicki dyskurs medyczny w językach angielskim i polskim w ujęciu lingwistycznym i metodycznym. Kraków: Fundacja Zdrowia Publicznego Uniwersyteckie Wydawnictwo Medyczne „Vesalius”.

Engeström, Y. 1987. Learning by Expanding: An activity theoretical approach to development research. Helsinki, Finland: Orienta-Konsultit Oy.

Europejski System Opisu Kształcenia Językowego: uczenie się, nauczanie, ocenianie. 2003. Warszawa: Wydawnictwa CODN.

Gabryś-Barker, D. 2011a: „Time as cultural construct: some preliminary remarks on the conceptualization of time in L1 and L2". (w) Aspects of Culture in Second Language Acquisition and Foreign Language Learning. (red. J. Arabski i A. Wojtaszek). Berlin, Heilderberg: Springer, str. 151-165.

Gabryś-Barker, D. 2011b: „Students mobility as a way of uniting cultures: A case study of an ERASMUS student". (w) Global Encounters: Pedagogical Paradigms and Educational Practices. (red. B. C. Swaffield i I. Guske). Newcastle upon Tyne: Cambridge Scholars Publishing, str. 275-289.

Hall, E. T. 1959. The Silent Language. New York: Doubleday \& Company.

Hall, E. T., Reed Hall, M. 1990. Understanding Cultural Differences: Keys to success in West Germany, France, and the United States. Yarmouth: Intercultural Press.

Hofstede, G. 1980. Culture's Consequences: International Difference in Work-related Values. Beverly Hills, CA: Sage Publications.

Hofstede, G. 1991. Cultures and Organizations: A Software of Mind. London: McGraw-Hill. Jaroszewska, A. 2007. Nauczanie języków obcych w nauczaniu wczesnoszkolnym. Rozwój świadomości wielokulturowej dziecka. Wrocław: Oficyna Wydawnicza ATUT.

Kramsch, C. 1993. Context and Culture. Oxford: Oxford University Press.

Kusiak, M. 2013. Reading Comprehension in Polish and English. Kraków: Wydawnictwo Uniwersytetu Jagiellońskiego.

Lázár, I. 2007: „Guidelines for the teaching of intercultural communicative competence (ICC)". (w) Developing and Assessing Intercultural Communicative Competence. A Guide for Language Teachers and Teacher Educators. (red. I. Lázár, M. Huber-Kriegler, D. Lussier, G. S. Matei i C. Peck). Strasbourg: European Centre for Modern Languages, str. 5-11.

Liddicoat, A. J., L. Papademetre, A. Scarino i M. Kohler (red.). 2003. Report on Intercultural Language Learning. Canberra ACT: Commonwealth of Australia.

MacDonald, M. 2000: „Strangers in a strange land: Fiction, culture, language”. (w) Target Culture - Target Language? (red. K. Seago i N. McBride). London: AFLS/CLIT, str. 137-155.

Martinelli, S. i M. Taylor (red.). 2000. Intercultural Learning. T-KIT No. 4. Strasbourg: Council of Europe.

Morris-Suzuki, T. 2005. The Past within Us. London: Verso. 
Munoz, C. C. i J. Luckmann. 2005. Transcultural Communication in Nursing. Wyd. 2. New York: Thomson/Delmar Learning.

National Standards for Language Education: The 5C's: Communication, Culture, Connections, Comparisons, Communities; Standards for Foreign Language Learning in the $21^{\text {st }}$ Century, 1999; Standards for Foreign Language Learning: Preparing for the $21^{\text {st }}$ Century. 1996. [online: http://www.globalteachinglearning.com/standards/5cs.shtml; DW 15. 06.2015].

Newton, J. 2012: „Teaching English for intercultural spoken communication: from CLT to iCLT". (w) Innovation and Creativity in ELT Methodology. Education in Competitive and Globalizing World. (red. H. P. Widodo i A. Cirocki). New York: Nova Sciences Publishers, Inc., str. 29-42.

Nishino, R. 2015. „Dialogues with shadows; Reflection of identity, history and travel”. Life Writing 12(1): 95-105 [DW 27. 01. 2015].

Paprocka-Piotrowska, U. 2007: „Stereotypy w dialogu interkulturowym - wprowadzenie do warsztatu". (w) Dydaktyka języków obcych na poczq̨tku XXI wieku. (red. M. Jodłowiec, A. Niżegorodcew). Kraków: Wydawnictwo Uniwersytetu Jagiellońskiego, str. 287-292.

Paprocka-Piotrowska, U. 2013. „Konceptualizacja przestrzeni i czasowniki ruchu w języku polskim i francuskim jako obcym". Neofilolog 40(1): 127-144.

Pieklarz, M. 2006. Stereotype und Affektivität im interkulturellen Fremdsprachenunterricht. Niepublikowana praca doktorska. Poznań: Uniwersytet im. Adama Mickiewicza.

Podstawa Programowa, 2009. Dziennik Ustaw Nr 4, poz. 17. Rozporządzenie Ministra Edukacji Narodowej z dnia 23 grudnia 2008 r. w sprawie podstawy programowej wychowania przedszkolnego oraz kształcenia ogólnego w poszczególnych typach szkół.

Puppel, S. 2007: „Filologia dawniej i dziś: kilka uwag o klasycznej i nowożytnej metodzie filologicznej". (w) For the Love of the Embedded Word - in Society, Culture and Education. (red. Z. Wąsik, A. Ciuk). Wrocław: Wydawnictwo Uniwersytetu Wrocławskiego, str. 7-17.

Romanowski, P. 2011. Developing Cross-Cultural Communication Competence in Foreign Language Classes (on the example of English). Niepublikowana praca doktorska. Kraków: Uniwersytet Jagielloński.

Róg, T. 2013. Intercultural Speakers and Study Abroad Programmes. The case of Erasmus students. LAP LAMBERT Academic Publishing: Saarbrücken.

Sapir, E. 1921. Language. New York: Harcourt, Brace and World.

Scrivener, J. 2011. Language Teaching. Oxford: Macmillan Publishers Ltd.

Siek-Piskozub, T. 2012: „Use of simulations for the development of intercultural communicative competence in EFL teacher education". (w) International Symposium on Language and Communication: Research trends and challenges. Proceedings Book. Izmir: Izmir University: 2277-2288.

Siek-Piskozub, T. 2013: „Using simulation to develop Intercultural Communication Competence in and EFL methodology seminar". (w) Psycholinguistic and Sociolinguistic Perspectives on Second Language Learning and Teaching. Studies in Honor of Waldemar Marton. (red. K. Droździał-Szelest i M. Pawlak). Berlin Heidelberg: Springer, str. 221-232. 
Siek-Piskozub, T. 2014: „Educating FL Teachers for the Role of Intercultural Mediators - Challenges and Options". (w) Intercultural Issues in the Era of Globalization. Studi@Naukowe 27 pod redakcja naukowq Sambora Gruczy. (red. P. Romanowski). Warszawa: Wydawnictwa Naukowe Instytutu Komunikacji Specjalistycznej i Interkulturowej Uniwersytetu Warszawskiego, str. 191-199. [online: https://portal.uw.edu.pl/web/snikla/home].

Szczepaniak-Kozak, A. 2010: „Interkulturowa kompetencja komunikacyjna z perspektywy nauczyciela języka angielskiego". (w) Kompetencja interkulturowa w teorii i praktyce językowej. (red. M. Mackiewicz). Poznań: Wydawnictwo Wyższej Szkoły Bankowej, str. 125-137.

The Hofstede Centre, Strategy - Culture - Change [online: http://geert-hofstede.com/ poland.html; DW 26.10.2015].

Weaver, G. 2001. American Cultural Values [online: www.gmfus.org/doc/mmf/American\%20Cultural\%20Values.pdf; DW 21.01.2015].

Werbińska, D. 2009. Dylematy etyczne nauczycieli języków obcych. Warszawa: Fraszka Edukacyjna.

Whorf, B. L. 1956. Language Thought, and Reality: Selected writings of Benjamin Lee Whorf (red. J. B. Carroll). New York: Wiley.

Wilczyńska, W. 2005: „Czego potrzeba do udanej komunikacji międzykulturowej?”. (w) Dydaktyka języków obcych a kompetencja kulturowa i komunikacja interkulturowa. (red. M. Mackiewicz). Poznań: Wydawnictwo Wyższej Szkoły Bankowej. Wygotski, L. S. 1989. Myślenie i mowa. Warszawa: Państwowe Wydawnictwo Naukowe. Zawadzka, E. 2004. Nauczyciel języków obcych w dobie przemian. Kraków: Impuls.

\section{Netografia}

http://sheffield.typepad.com/articles/assessinginterculturalsensitivityinmissioncan didatesandpersonnel.pdf. 


\section{Aneks}

Narzędzia mediacji

(język angielski, materiały dydaktyczne, techniki symulacji i odgrywania ról,

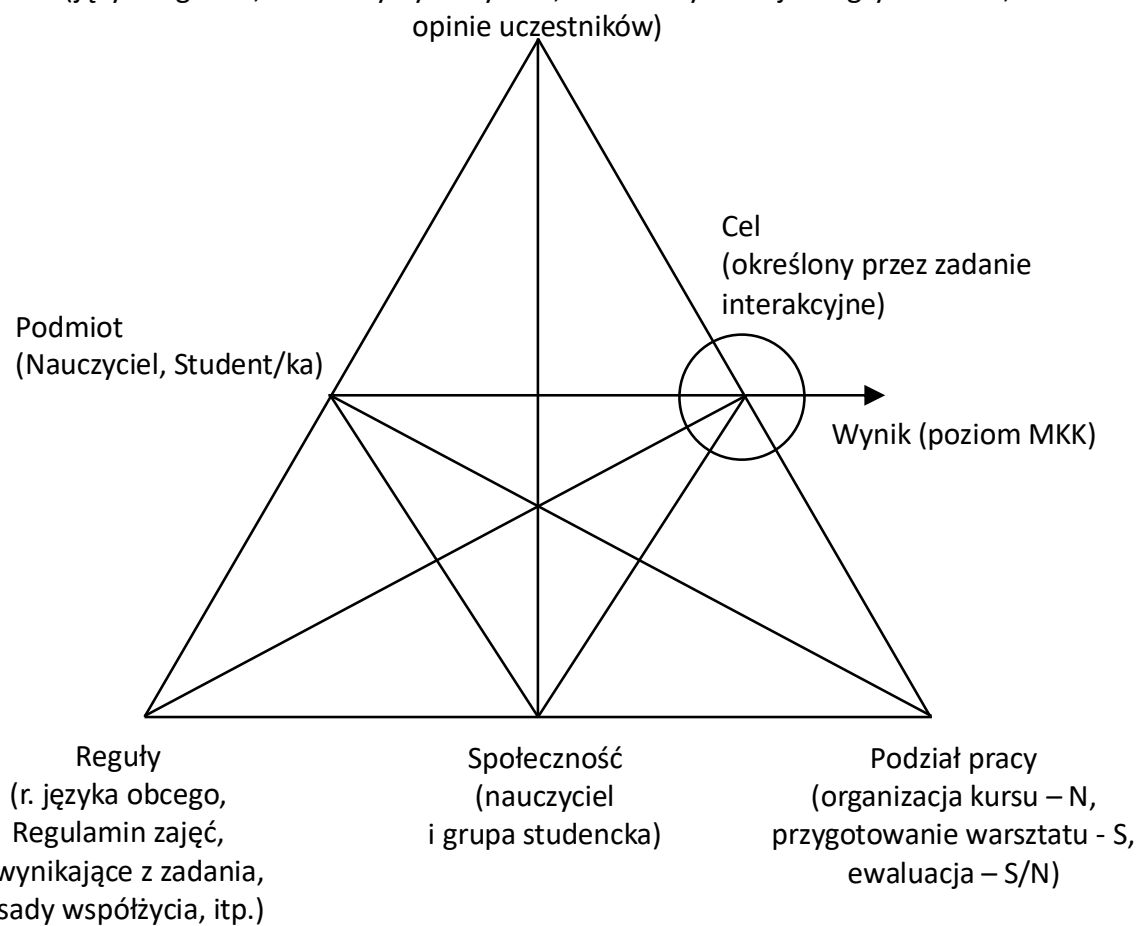

Rysunek 2: Struktura uczenia się na zajęciach z MKK według teorii aktywności (adaptacja modelu Engeströma, 1987: 78). 